\title{
Review Article \\ Protein Redox Modification as a Cellular Defense Mechanism against Tissue Ischemic Injury
}

\author{
Liang-Jun Yan \\ Department of Pharmaceutical Sciences, UNT System College of Pharmacy, University of North Texas Health Science Center, \\ 3500 Camp Bowie Boulevard, RES-314E, Fort Worth, TX 76107, USA
}

Correspondence should be addressed to Liang-Jun Yan; liang-jun.yan@unthsc.edu

Received 3 March 2014; Accepted 16 April 2014; Published 5 May 2014

Academic Editor: Jianping Jin

Copyright (C) 2014 Liang-Jun Yan. This is an open access article distributed under the Creative Commons Attribution License, which permits unrestricted use, distribution, and reproduction in any medium, provided the original work is properly cited.

\begin{abstract}
Protein oxidative or redox modifications induced by reactive oxygen species (ROS) or reactive nitrogen species (RNS) not only can impair protein function, but also can regulate and expand protein function under a variety of stressful conditions. Protein oxidative modifications can generally be classified into two categories: irreversible oxidation and reversible oxidation. While irreversible oxidation usually leads to protein aggregation and degradation, reversible oxidation that usually occurs on protein cysteine residues can often serve as an "on and off" switch that regulates protein function and redox signaling pathways upon stress challenges. In the context of ischemic tolerance, including preconditioning and postconditioning, increasing evidence has indicated that reversible cysteine redox modifications such as S-sulfonation, S-nitrosylation, S-glutathionylation, and disulfide bond formation can serve as a cellular defense mechanism against tissue ischemic injury. In this review, I highlight evidence of cysteine redox modifications as protective measures in ischemic injury, demonstrating that protein redox modifications can serve as a therapeutic target for attenuating tissue ischemic injury. Prospectively, more oxidatively modified proteins will need to be identified that can play protective roles in tissue ischemic injury, in particular, when the oxidative modifications of such identified proteins can be enhanced by pharmacological agents or drugs that are available or to be developed.
\end{abstract}

\section{Introduction}

Increasing evidence continues to support the concept that reactive oxygen species (ROS) and reactive nitrogen species (RNS) can exert great beneficial effects on cellular adaptation to stress challenges and cell survival [1-5]. This is particularly true in the context of ischemic tolerance that includes preconditioning and postconditioning; both of which are used to prepare tissues to tolerate injuries against lethal ischemic occurrence by triggering endogenous adaptive and defensive responses [5-13]. Evidence supporting the involvement of ROS and RNS in ischemic tolerance comes directly from the observations that administration of antioxidants before or during the induction of ischemic tolerance can abolish the protective effects of either preconditioning or postconditioning [14-20]. As one of the means that ROS/RNS work is via modifying proteins, protein redox modifications can thus execute the beneficial effects of ROS/RNS [21-26]. In this review, I will summarize evidence that protein redox modifications, in particular, reversible modifications on protein cysteine residues when induced by preconditioning or postconditioning, can serve as a cellular defense mechanism against tissue ischemic injury. Evidence presented indicates that protein redox modifications can serve as therapeutic targets in tissue ischemic injury.

\section{Protein Redox Modifications}

Under stress conditions, cells can produce an elevated level of reactive oxygen species (ROS) and reactive nitrogen species (RNS) [27, 28], which, in turn, can oxidize or modify proteins [29-32]. As shown in Figure 1, protein oxidation can be classified into two general categories. One is irreversible and the other is reversible. Irreversible oxidation usually leads to protein aggregation and degradation. This type of oxidation includes formation of protein carbonyls [33], nitrotyrosine [34], and sulfonic acids [35]. On the other hand, reversible 


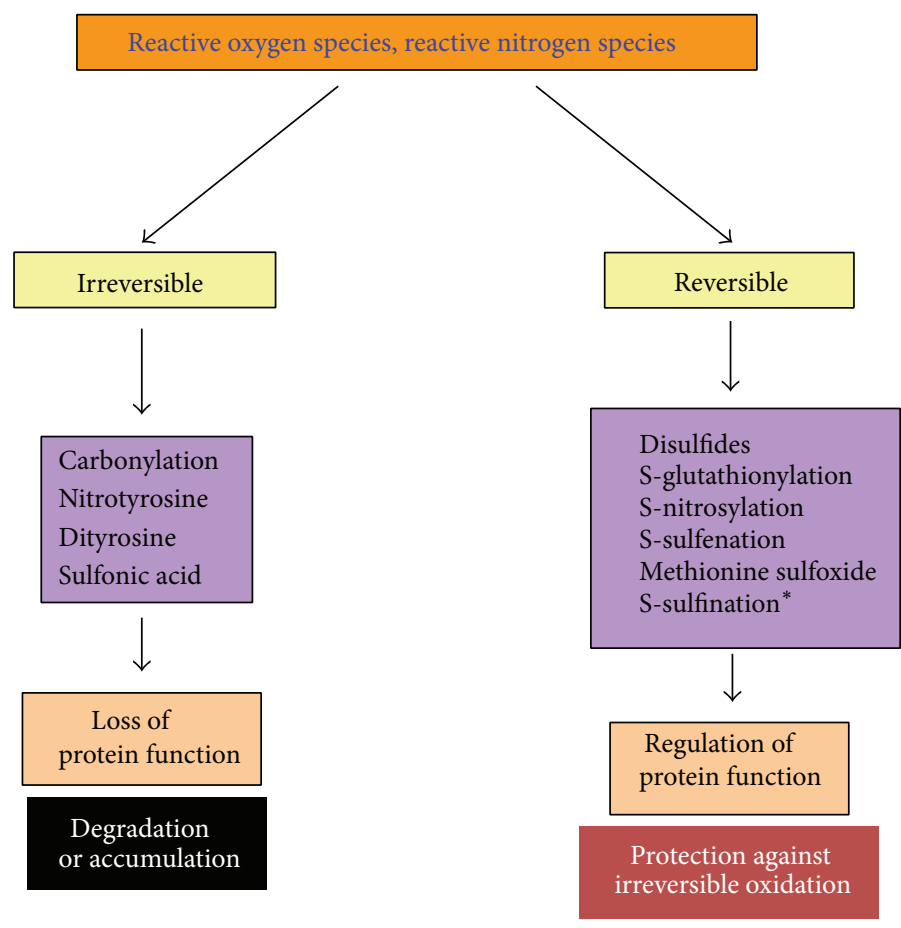

Figure 1: Classification of protein oxidative modifications into two categories: irreversible oxidation and reversible oxidation. * Note: only a few studies so far have reported that sulfinic acid (S-sulfinition) formation could be reversible [180, 181].

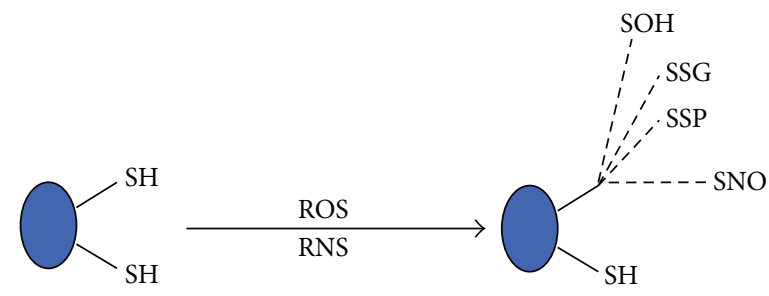

-SOH: sulfenic acid (S-sulfenation)

-SNO: S-nitrosylation

-SSG: S-glutathionylation

-SSP: inter- or intraprotein disulfides

FIGURE 2: Reversible cysteine modification products that are widely studied. These products include S-sulfenation (sulfenic acid, -SOH), S-nitrosylation (-SNO), S-glutathionylation (-P-S-S-G), and either intra- or interdisulfides.

protein oxidation is usually involved in redox signaling pathways and regulation of protein structure and function [36-38]. This type of oxidation often occurs on protein cysteine residues leading to formation of S-sulfenation, Snitrosylation, disulfides, and S-glutathionylation [35, 39, 40] (Figure 2). Additionally, formation of methionine sulfoxide, involving methionine sulfoxide reductase [41-44], is also a reversible process and has been shown to be involved in protection against ischemic injury [45-47]. It should be pointed out that, strictly speaking, disulfide formation ( $\mathrm{P}-$ S-S-P) and S-glutathionylation (P-S-S-G) are not oxidative modifications as the end products do not contain an oxygen atom like those found in S-nitrosylation (-SNO) and S-sulfenation (-SOH). Nonetheless, formation of both disulfides and glutathionylation requires the presence of reactive oxygen species such as hydrogen peroxide [48-56]. Therefore, it would be more appropriate to name these two modifications as redox modifications.

\section{Production of Reactive Oxygen Species (ROS) and Reactive Nitrogen Species (RNS)}

While all endogenous RNS originate from nitric oxide synthases, ROS can be produced by many cellular systems. Among which, mitochondria remain as a major cellular site 
for ROS production [28, 57-59]. It has been established that mitochondrial complexes I and III are the major two sites for mitochondrial ROS production $[57,58]$. Other enzyme systems in mitochondria that can generate ROS include complex II [60], $\alpha$-keto acid dehydrogenase complexes that contain dihydrolipoamide dehydrogenase [61-65]. Outside mitochondria, NADPH oxidase $[66,67]$, xanthine oxidase [68, 69], and cytochrome P-450 enzymes [70] can also generate ROS. It has been recently reported that the $\alpha$-keto acid dehydrogenase complexes can generate more ROS than complex I [71]. The initial species is always a superoxide anion, which can be dismutated to $\mathrm{H}_{2} \mathrm{O}_{2}$ [72-74]. The latter can decay to form hydroxyl radical in the presence of metal ions [75]. Additionally, when superoxide meets nitric oxide, peroxynitrite is formed $[76,77]$. Both hydroxyl radical and peroxynitrite are known to be highly reactive towards proteins $[78,79]$.

\section{Balance and Imbalance between Oxidants and Antioxidants}

Production of ROS and RNS is a well-controlled process under normal conditions $[80,81]$. This is because cells have a variety of antioxidant defense systems. These include but are not limited to superoxide dismutase, catalase, glutathione peroxidase, thioredoxin, and peroxiredoxin [27]. Moreover, there are also small antioxidant molecules such as vitamin $\mathrm{C}$, vitamin E, glutathione, and coenzyme Q [27]. Under normal physiological conditions, a balance between ROS production and antioxidant defense is well maintained [53, 82]. However, under stress or pathophysiological conditions, more ROS and RNS can be produced that can overwhelm the cellular antioxidant defense system, leading to severe oxidative stress and oxidative damage $[80,83]$. On the other hand, intentionally induced oxidative stress can serve as a defense mechanism against further oxidative challenges [80, 83-87]. This is known as hormetic effect [88-90] or "positive oxidative stress" and are often explored as a protective approach in ischemic tissue injuries [26], a phenomenon often termed as ischemic tolerance that includes both preconditioning and postconditioning $[7,17,91]$.

\section{Ischemic Tolerance: Preconditioning and Postconditioning}

Preconditioning is a prophylactic approach, which often involves noninjurious stimulation of the tissues that are of interest [7, 17, 91]. Such stimulation can prepare the tissues to resist further challenges that are lethal $[7,17$, 91]. Induction of preconditioning can be achieved by many ways, including short episodes of ischemia reperfusion [92], treatment with chemicals or drugs that are often inhibitors of mitochondrial electron transporter complexes [26, 93], hyperoxia [94, 95], and hypoxia [96], as well as remote preconditioning [97]. Remote preconditioning means that the tissues that receive preconditioning can defend other tissues against ischemic injuries. Therefore, the target to be preconditioned and the target to be protected are not the same in the settings of remote preconditioning. As opposed to that of preconditioning, postconditioning is the interruption or intervention at the onset of reperfusion after an ischemia has occurred [98-102]. Therefore, postconditioning may be more clinically relevant as ischemic occurrence is generally not a predictable event. Nonetheless, preconditioning is still intensively studied because investigating how tissues respond to preconditioning may identify endogenous therapeutic targets for treatment of ischemic injury $[103,104]$. Moreover, both preconditioning and postconditioning have been shown to involve similar signaling pathways or trigger similar defense mechanisms [100, 105-107].

\section{Reversible Protein Cysteine Modifications and Ischemic Tolerance}

In the context of ischemic tolerance including preconditioning and postconditioning, cysteine redox modifications have been explored extensively. This is because cysteine oxidation is closely associated with cellular redox potential reflected by the ratio between GSH/GSSG and NADH/NAD ${ }^{+}[108,109]$. Moreover, cysteine residues can undergo reversible modifications that are involved in an "on and off" switch during stress conditions [36, 110-112]. Therefore, reversible cysteine modifications are often involved in regulating redox signaling pathways and protein function [37, 113, 114]. Accordingly, I will cover only reversible cysteine modifications and their protective roles in ischemic injury in in this review. These include S-sulfenation, S-nitrosylation, S-glutathionylation, and disulfide formation. But, before discussing each of the four modifications, I would like to briefly introduce a general method for analysis of reversible cysteine modifications as the method has contributed significantly in the paradigms to be presented below in this review.

\section{General Detection Method for Reversible Cysteine Modifications}

As cysteine oxidation does not involve a change in optical density of the modified proteins, a probe is always needed for the detection of cysteine modifications [115]. In fact the approaches are quite similar for S-sulfenation, Snitrosylation, and S-glutathionylation. Figure 3 shows one of the general procedures for detection of cysteine oxidation products. This widely used method is often called biotin switch assay [116]. The steps involve blocking unmodified cysteine residues with alkylating reagents such as N-ethylmaleimide (NEM), reducing the modified cysteine residues using a specific reducing reagent for each modified species $[38,117]$. For example, ascorbic acid is used for the reduction of S-nitrosylation [118], arsenite is used for the reduction of S-sulfenation [119], and glutaredoxin is used for the reduction of S-glutathionylation [120, 121]. This is followed by relabeling of the reduced cysteine residues using biotin conjugated with an alkylating reagent such as NEM. This approach not only facilitates gel-based detection as biotin can be readily recognized by streptavidin, but also can be conducive to affinity purification of the modified 


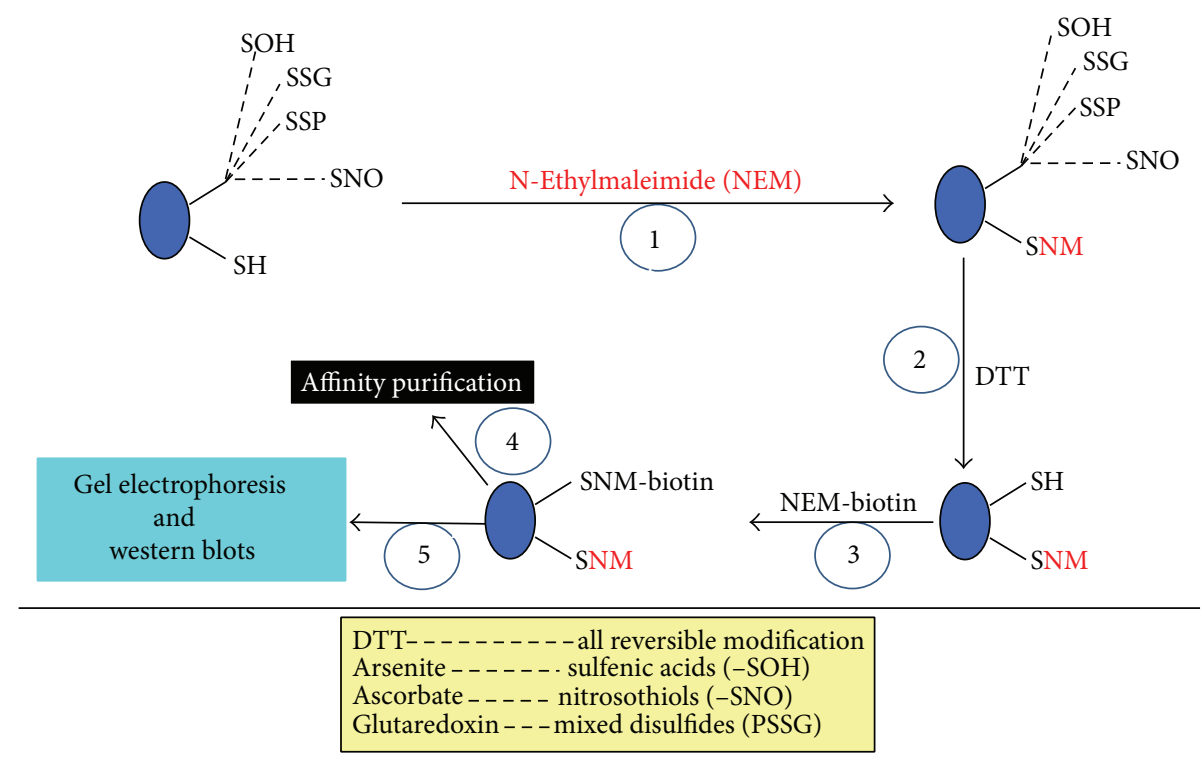

Figure 3: Analysis of reversible cysteine redox modifications. What is shown is a one of the popular methods generally called a "biotin switch" assay, which involves alkylating the free thiol groups (step 1), reducing the modified cysteine residues using specific reductant for each oxidation product (step 2), and relabeling of the newly generated free thiol groups using biotin conjugated probes (step 3). Following biotinylation, the samples can be further analyzed by either western blot (step 5) or affinity purification (step 4). Note that protein sulfenic acids can be directly labeled by dimedone conjugated biotin probes as described in the text.

proteins. Additionally, NEM-biotin labeling can also pinpoint the site of modifications when used in conjunction with mass spectrometric peptide sequencing. It should be noted that, for the detection of protein sulfenic acids, biotin conjugated dimedone probes have been developed that only reacts with $-\mathrm{SOH}[122,123]$; therefore no blocking and reducing steps are needed. For the detection and quantification of Sglutathionylation, the enzyme glutaredoxin is needed in the presence of GSH. DTT and 2-mercaptoethanol are nonspecific reducing reagents; hence they are not good for a specific modifying species.

\section{Paradigms of Reversible Protein Cysteine Modifications as a Defense Mechanism in Ischemic Injury}

8.1. S-Sulfenation (-SOH). S-Sulfenation or protein sulfenic acid $(-\mathrm{SOH})$ is now attracting increasing attention because this cysteine redox modification product can now be readily trapped and quantified $[115,123]$. Moreover, although once considered a transient product of cysteine oxidation adduct, stable $-\mathrm{SOH}$ has been found to exist that plays an "on and off" switch in regulating protein function and redox signaling [40]. An elegant model of protein sulfenic acid formation in protecting ischemic tissue injury is the enzyme aldose reductase that has been studied thoroughly by Dr. Bhathagar's group at University of Louisville. This group initially found that AR could be activated by ischemic reperfusion in the heart, and this activation was due to the formation of a sulfenic acid on cysteine residue 298 [124]. Furthermore, this sulfenation process of cysteine 298 was found to be achieved by peroxynitrite [125], a highly reactive species formed between superoxide anion and nitric oxide [126]. The group next found that this activation of AR via cysteine sulfenic acid formation was regulated by the PI3K/AKT/eNOS signaling pathway [125]. As this pathway is known to be involved in protection against ischemic injury $[127,128]$, AR activation by sulfenic acid formation on cysteine 298 thus is suggested to be involved in cardioprotection against cardiac injury, which is further supported by the observation that AR inhibitors such as sorbitol or tolrestat, when applied before ischemia or at the onset of reperfusion, hindered postischemic recovery in the heart [125]. Interestingly, as this seems to be the end of the story, this laboratory went further and demonstrated that formation of AR-SOH on cysteine 298 during cardiac ischemia reperfusion could be reversed back to AR-SH [129], which involved two enzymes, glutathione S-transferase converting $\mathrm{AR}-\mathrm{SOH}$ to AR-SSG, and glutaredoxin converting AR-SSG to AR-SH [129]. Therefore, both enzymes may be involved in regulation of $\mathrm{AR}-\mathrm{SOH}$ reduction when tissue oxygen and nutrient supply is resumed after an ischemic incident.

8.2. S-Nitrosylation (-SNO). Protein cysteine nitrosylation (P-SNO), another form of reversible modification, has been studied by numerous investigators. The role of this modification has been thought to be equivalent to that of protein phosphorylation $[130,131]$. It not only has detrimental effects on protein function and cell survival $[132,133]$, but also can exert beneficial effects under a variety of pathophysiological conditions $[134,135]$. In the context of tissue ischemic injury, it has been found that overall protein -SNO, in connection with the activation of the PI3K/AKT signaling pathway, increases after postconditioning in the heart [136], indicating that nitrosylation of individual proteins play a protective role 
in ischemic injury. This is indeed the case as presented in the following two examples.

8.2.1. S-Nitrosylation of TRIM72 at Cysteine-144 Is Cardioprotective. Tripartite motif-containing protein 72 (TRIM72) is a membrane repair protein that can undergo posttranslational modifications leading to its either activation or degradation. Using the biotin switch assay shown in Figure 3, Kohr et al. reported that TRIM72 exhibited an elevated level of SNO at cysteine-144 upon ischemic preconditioning [137]. As ischemic preconditioning is an established approach for cardioprotection against ischemic injury [138], the authors hypothesized that increase in TRIM72's cysteine-144 nitrosylation protects against cardiac ischemic injury. The authors tested the hypothesis by mutating C144 to a serine residue (C144S) in a tissue culture system using HEK-293 cells that lack TRIM72. This mutation would abolish the proteins Snitrosylation at $\mathrm{C} 144$, hence changing the protein's property and function. Indeed, the authors found that after the mutation, protein levels of TRIM72 (wildtype) but not TRIM72C114S (mutant) were decreased upon $\mathrm{H}_{2} \mathrm{O}_{2}$ treatment, and this decrease correlated with enhanced $\mathrm{H}_{2} \mathrm{O}_{2}$-induced cell death in the wild type cells. Moreover, treatments of the cells with an S-nitrosylating agent S-nitrosoglutathione (GSNO) [139] could maintain TRIM72's protein level and reduce cell death. The authors further demonstrated that GSNO induced TRIM72 nitrosylation stopped ischemia reperfusion triggered decrease in TRIM72 levels and decreased infarct size in heart ischemia reperfusion. Thus, cys144-SNO of TRIM72 prevents degradation of TRIM72 upon ischemic challenge and thus preserves its membrane repair capacity.

8.2.2. S-Nitrosylation of Mitochondrial Complex I ND3 Subunit Participates in Cardioprotection against Ischemic Injury. Complex I is the electron entry point in the mitochondrial electron transport chain. It has at least 45 subunits in the mammalian systems and many of them are redox sensitive [140-142]. Dysfunction of complex I is thought to be a causal factor in the pathogenesis of many mitochondrial diseases including ischemic injury [143-145]. Recently, Chouchani et al. reported that S-nitrosylation of the complex I subunit ND3 is involved in cardioprotection against ischemic insult [146]. The authors reported that S-nitrosylation of ND3-cysteine-39 inhibited complex I activity and slowed mitochondrial recovery at the initial minutes of reperfusion, hence attenuating ROS generation upon sudden oxygen resupply, leading to less oxidative damage and tissue necrosis. Interestingly, ND3 only became accessible to nitrosylation after an ischemic insult as mitoSNO, a membrane permeable nitrosylating agent, could only provide the protective effect at the onset of reperfusion via ND3 cysteine-39 nitrosylation. As mitoSNO was applied during reperfusion and its protective effect could only be observed when administered at the onset of reperfusion, this study provides an elegant postconditioning paradigm whereby S-nitrosylation could serve as one mechanism contributing to postconditioning-induced ischemic tolerance.
8.3. S-Glutathionylation. Well-defined roles of protein Sglutathionylation in ischemic tolerance have not been clearly reported in the literature. Nonetheless, there are direct link that protein S-glutathionylation induced by preconditioning prevents cell death and enhances cell survival. The results of two studies will be summarized here. The first one is S-glutathionylation of mitochondrial adenine nucleotide translocase (ANT) induced by carbon monoxide preconditioning [147]; and the second one is S-glutathionylation of ryanodine receptor 2 induced by tachycardia preconditioning via elevation of NADPH oxidase activity. In the first study, Queiroga et al. reported that carbon monoxide prevents mitochondrial permeability transition pore opening and cell death via S-glutathionylation of ANT [147]. In particular, using nonsynaptic mitochondria isolated from rat brain and primary astrocytes prepared from the cortex of neonatal rats, the authors found that carbon monoxide could partially inhibit loss of mitochondrial membrane potential, the opening of mitochondrial membrane permeability transition pore, mitochondrial swelling, and cytochrome c release. To understand the underlying mechanisms, the authors further found that carbon monoxide could modulate ANT activity as $\mathrm{ADP} / \mathrm{ATP}$ exchange rate was enhanced. As ANT is part of the mitochondrial membrane permeability transition pore [148], this enhancement of ANT activity thus also prevented pore opening. Moreover, it was further found that the modulation of ANT activity was due to ANT glutathionylation caused by carbon monoxide-induced ROS production. It should be noted that the site of glutathionylation on the ANT molecule was not identified in this study.

In the second study, Sánchez et al. reported that while electrically induced tachycardia can effectively create myocardial preconditioning, the mechanisms remain elusive [149]. Therefore, the authors set out to elucidate the underlying mechanisms. Focusing on sarcoplasmic reticulum (SR) isolated from dog cardiac ventricular muscle, they found that preconditioning tachycardia increased NADPH oxidase activity by nearly $200 \%$ as measured by NADPH dependent superoxide production. This increase in enzymatic activity was due to the enhanced association of racl with the NADPH oxidase cytosolic subunit p47 (phox) to the microsomal fraction without altering the content of the enzyme's membrane subunit gp91 (phox). As an elevated level of superoxide can induce protein S-glutathionylation, the author further found that cardiac ryanodine receptor 2 (RyR2) was Sglutathionylated under their experimental conditions. Conversely, when catalase, superoxide dismutase, and NADPH oxidase inhibitors were added in the experimental system, RyR2 S-glutathionylation was greatly attenuated, indicating a potential link between RyR2 glutathionylation and tachycardia preconditioning. Interestingly, this same laboratory further reported that exercise could also produce a preconditioning effect by increasing NADPH oxidase activity and RyR2 S-glutathionylation [150]. Similar to the ANT studies presented above, the site of modification on Ry2R was also not pinpointed in this study.

8.4. Disulfides. Numerous studies have demonstrated that oxidative stress-induced disulfide formation can be beneficial 
to cell survival [151-155]. An excellent study by Fourquet et al. [156] presented a well-delineated role of protein disulfide formation in activation of the Nrf2 signaling pathway that regulates the expression of the second phase defensive enzymes such as hemeoxygenase-1 (HO-1) and $\mathrm{NAD}(\mathrm{P}) \mathrm{H}$ dehydrogenase quinone-1 (NQO-1) [157]. Using Hela cells treated with $\mathrm{H}_{2} \mathrm{O}_{2}$, nitric oxide, and hypochlorite, the authors found that Keapl, a protein that controls the fate of Nrf2, can form intramolecular disulfides, leading to release and nuclear translocation of Nrf2. The authors further found that cysteine-151 of Keap1 was involved in disulfide bond formation between two molecules of Keapl, forming a Keap1 homodimer. This formation of Keapl homodimer is important for Nrf2 release from the Keap1-Nrf2 complex as mutation of cysteine-151 led to an unstabilized form of Nrf2. Additionally, the authors also found that, when the thioredoxin and glutathione pathways were inactivated, Keap1 intramolecular disulfide bond formation was constitutive, leading to a stable Nrf2 molecule in the cell. Therefore, this study further demonstrates that Keap1 cysteine-151 disulfide bond formation is at least one of the mechanism by which cells utilize to resist ischemic injury by upregulating the second phase antioxidative proteins [158-166], which include thioredoxin reductase, glutamate-cysteine ligase (GCL), glutathione S-transferase, HO-1, and NQO-1, [157, 167-171].

\section{Summary and Perspective}

Protein redox modification is a double-edged sword. While there is no doubt that protein redox modifications can have detrimental effects on cell survival [172-179], there is also increasing evidence, as summarized in this review, that redox modification of certain proteins, when induced purposely by approaches that trigger positive oxidative stress [26], can play a protective role in tissue ischemic injury. Studying how proteins respond to oxidative modifications in the settings of preconditioning and postconditioning, may identify novel proteins as potential therapeutic targets for treatment of ischemia-related diseases, in particular, when such modifications can be enhanced by pharmacological agents.

\section{Conflict of Interests}

The author declares that there is no conflict of interests regarding the publication of this paper.

\section{Acknowledgment}

This work was supported in part by National Institute of Neurological Disorders and Stroke (R01NS079792 to LiangJun Yan).

\section{References}

[1] G. Groeger, C. Quiney, and T. G. Cotter, "Hydrogen peroxide as a cell-survival signaling molecule," Antioxidants and Redox Signaling, vol. 11, no. 11, pp. 2655-2671, 2009.
[2] D. Knoefler, M. Thamsen, M. Koniczek, N. J. Niemuth, A. K. Diederich, and U. Jakob, "Quantitative in vivo redox sensors uncover oxidative stress as an early event in life," Molecular Cell, vol. 47, pp. 767-776, 2012.

[3] G. Groeger, F. Doonan, T. G. Cotter, and M. Donovan, "Reactive oxygen species regulate prosurvival ERK1/2 signaling and bFGF expression in gliosis within the retina," Investigative Ophthalmology \& Visual Science, vol. 53, pp. 6645-6654, 2012.

[4] E. Bevilacqua, S. Z. Gomes, A. R. Lorenzon, M. S. Hoshida, and A. M. Amarante-Paffaro, "NADPH oxidase as an important source of reactive oxygen species at the mouse maternal-fetal interface: putative biological roles," Reproductive BioMedicine Online, vol. 25, pp. 31-43, 2012.

[5] A. L. Müller and N. S. Dhalla, "Mechanisms of the beneficial actions of ischemic preconditioning on subcellular remodeling in ischemic-reperfused heart," Current Cardiology Reviews, vol. 6, no. 4, pp. 255-264, 2010.

[6] F. Wiegand, W. Liao, C. Busch et al., "Respiratory chain inhibition induces tolerance to focal cerebral ischemia," Journal of Cerebral Blood Flow and Metabolism, vol. 19, no. 11, pp. 12291237, 1999.

[7] F. Bosetti, G. Yu, R. Zucchi, S. Ronca-Testoni, and G. Solaini, "Myocardial ischemic preconditioning and mitochondrial F1F0-ATPase activity," Molecular and Cellular Biochemistry, vol. 215, no. 1-2, pp. 31-37, 2000.

[8] K. Kitagawa, "CREB and cAMP response element-mediated gene expression in the ischemic brain," FEBS Journal, vol. 274, no. 13, pp. 3210-3217, 2007.

[9] K. Kitagawa, "Ischemic tolerance in the brain: endogenous adaptive machinery against ischemic stress," Journal of Neuroscience Research, vol. 90, no. 5, pp. 1043-1054, 2012.

[10] C. W. Yang, H. J. Ahn, H. J. Han et al., "Pharmacological preconditioning with low-dose cyclosporine or FK506 reduces subsequent ischemia/reperfusion injury in rat kidney," Transplantation, vol. 72, no. 11, pp. 1753-1759, 2001.

[11] T. Ravingerová, "Intrinsic defensive mechanisms in the heart: a potential novel approach to cardiac protection against ischemic injury," General Physiology and Biophysics, vol. 26, no. 1, pp. 313, 2007.

[12] R. A. Stetler, F. Zhang, C. Liu, and J. Chen, "Chapter 9 Ischemic tolerance as an active and intrinsic neuroprotective mechanism," Handbook of Clinical Neurology, vol. 92, pp. 171195, 2009.

[13] D. Della-Morte, F. Guadagni, R. Palmirotta et al., "Genetics and genomics of ischemic tolerance: focus on cardiac and cerebral ischemic preconditioning," Pharmacogenomics, vol. 13, pp. 17411757, 2012.

[14] G. Lebuffe, P. T. Schumacker, Z. Shao, T. Anderson, H. Iwase, and T. L. Vanden Hoek, "ROS and NO trigger early preconditioning: relationship to mitochondrial KATP channel," The American Journal of Physiology-Heart and Circulatory Physiology, vol. 284, no. 1, pp. H299-H308, 2003.

[15] V. Fernández, G. Tapia, P. Varela et al., "Causal role of oxidative stress in liver preconditioning by thyroid hormone in rats," Free Radical Biology and Medicine, vol. 44, no. 9, pp. 1724-1731, 2008.

[16] R. Zucchi, G. Yu, P. Galbani, M. Mariani, G. Ronca, and S. Ronca-Testoni, "Sulfhydryl redox state affects susceptibility to ischemia and sarcoplasmic reticulum $\mathrm{Ca}^{2+}$ release in rat heart implications for ischemic preconditioning," Circulation Research, vol. 83, no. 9, pp. 908-915, 1998.

[17] T. Mori, H. Muramatsu, T. Matsui, A. Mckee, and T. Asano, "Possible role of the superoxide anion in the development 
of neuronal tolerance following ischaemic preconditioning in rats," Neuropathology and Applied Neurobiology, vol. 26, no. 1, pp. 31-40, 2000.

[18] Y. Bhagatte, D. Lodwick, and N. Storey, "Mitochondrial ROS production and subsequent ERK phosphorylation are necessary for temperature preconditioning of isolated ventricular myocytes," Cell Death and Disease, vol. 3, article e345, 2012.

[19] L. Zuo, W. J. Roberts, R. C. Tolomello, and A. T. Goins, "Ischemic and hypoxic preconditioning protect cardiac muscles via intracellular ROS signaling," Frontiers in Biology, vol. 8, pp. 305-311, 2013.

[20] F. Jiang, Y. Zhang, and G. J. Dusting, "NADPH oxidasemediated redox signaling: roles in cellular stress response, stress tolerance, and tissue repair," Pharmacological Reviews, vol. 63, no. 1, pp. 218-242, 2011.

[21] F. Hochgräfe, J. Mostertz, D. Pöther, D. Becher, J. D. Helmann, and M. Hecker, "S-cysteinylation is a general mechanism for thiol protection of Bacillus subtilis proteins after oxidative stress," The Journal of Biological Chemistry, vol. 282, no. 36, pp. 25961-25985, 2007.

[22] J. T. Hancock, "The role of redox mechanisms in cell signalling," Molecular Biotechnology, vol. 43, no. 2, pp. 162-166, 2009.

[23] D. Shao, S. Oka, C. D. Brady, J. Haendeler, P. Eaton, and J. Sadoshima, "Redox modification of cell signaling in the cardiovascular system," Journal of Molecular and Cellular Cardiology, vol. 52, no. 3, pp. 550-558, 2012.

[24] B. Lizama-Manibusan and B. McLaughlin, "Redox modification of proteins as essential mediators of CNS autophagy and mitophagy," FEBS Letters, vol. 587, pp. 2291-2298, 2013.

[25] N. Gould, P. T. Doulias, M. Tenopoulou, K. Raju, and H. Ischiropoulos, "Regulation of protein function and signaling by reversible cysteine S-nitrosylation," The Journal of Biological Chemistry, vol. 288, pp. 26473-26479, 2013.

[26] L. J. Yan, "Positive oxidative stress in aging and aging-related disease tolerance," Redox Biology, vol. 2, pp. 165-169, 2014.

[27] M. J. Jackson, S. Papa, J. Bolaños et al., "Antioxidants, reactive oxygen and nitrogen species, gene induction and mitochondrial function," Molecular Aspects of Medicine, vol. 23, no. 1-3, pp. 209-285, 2002.

[28] M. P. Murphy, "How mitochondria produce reactive oxygen species," Biochemical Journal, vol. 417, no. 1, pp. 1-13, 2009.

[29] L. J. Yan, R. L. Levine, and R. S. Sohal, "Oxidative damage during aging targets mitochondrial aconitase," Proceedings of the National Academy of Sciences of the United States of America, vol. 94, pp. 11168-11172, 1997.

[30] L. Yan, J. K. Lodge, M. G. Traber, and L. Packer, "Apolipoprotein B carbonyl formation is enhanced by lipid peroxidation during copper-mediated oxidation of human low-density lipoproteins," Archives of Biochemistry and Biophysics, vol. 339, no. 1, pp. 165171, 1997.

[31] L. Yan and R. S. Sohal, "Prevention of flight activity prolongs the life span of the housefly, Musca domestica, and attenuates the age-associated oxidative damamge to specific mitochondrial proteins," Free Radical Biology and Medicine, vol. 29, no. 11, pp. 1143-1150, 2000.

[32] L. Yan and R. S. Sohal, "Mitochondrial adenine nucleotide translocase is modified oxidatively during aging," Proceedings of the National Academy of Sciences of the United States of America, vol. 95, no. 22, pp. 12896-12901, 1998.

[33] L. J. Yan, "Analysis of oxidative modification of proteins," Current Protocols in Protein Science, Chapter 14, Unit 14 14, 2009.
[34] R. Radi, "Protein tyrosine nitration: biochemical mechanisms and structural basis of functional effects," Accounts of Chemical Research, vol. 46, pp. 550-559, 2013.

[35] K. G. Reddie and K. S. Carroll, "Expanding the functional diversity of proteins through cysteine oxidation," Current Opinion in Chemical Biology, vol. 12, no. 6, pp. 746-754, 2008.

[36] S. B. Wall, J. Y. Oh, A. R. Diers, and A. Landar, "Oxidative modification of proteins: an emerging mechanism of cell signaling," Frontiers in Physiology, vol. 3, article 369, 2012.

[37] H. J. Forman, J. M. Fukuto, and M. Torres, "Redox signaling: thiol chemistry defines which reactive oxygen and nitrogen species can act as second messengers," The American Journal of Physiology-Cell Physiology, vol. 287, no. 2, pp. C246-C256, 2004.

[38] L. J. Yan, N. Sumien, N. Thangthaeng, and M. J. Forster, "Reversible inactivation of dihydrolipoamide dehydrogenase by mitochondrial hydrogen peroxide," Free Radical Research, vol. 47, pp. 123-133, 2013.

[39] Y. M. Janssen-Heininger, J. D. Nolin, S. M. Hoffman et al., "Emerging mechanisms of glutathione-dependent chemistry in biology and disease," Journal of Cellular Biochemistry, vol. 114, pp. 1962-1968, 2013.

[40] L. B. Poole, "Formation and functions of protein sulfenic acids," Current Protocols in Toxicology, Chapter 17, Unit 17 11, 2004.

[41] T. Hoshi and S. H. Heinemann, "Regulation of cell function by methionine oxidation and reduction," The Journal of Physiology, vol. 531, no. 1, pp. 1-11, 2001.

[42] S. Boschi-Muller, A. Gand, and G. Branlant, "The methionine sulfoxide reductases: catalysis and substrate specificities," Archives of Biochemistry and Biophysics, vol. 474, no. 2, pp. 266273, 2008.

[43] R. L. Levine, J. Moskovitz, and E. R. Stadtman, "Oxidation of methionine in proteins: roles in antioxidant defense and cellular regulation," IUBMB Life, vol. 50, no. 4-5, pp. 301-307, 2000.

[44] J. Moskovitz, S. Bar-Noy, W. M. Williams, J. Requena, B. S. Berlett, and E. R. Stadtman, "Methionine sulfoxide reductase (MsrA) is a regulator of antioxidant defense and lifespan in mammals," Proceedings of the National Academy of Sciences of the United States of America, vol. 98, no. 23, pp. 12920-12925, 2001.

[45] H. Zhao, J. Sun, A. M. Deschamps et al., "Myristoylated methionine sulfoxide reductase A protects the heart from ischemiareperfusion injury," The American Journal of Physiology-Heart and Circulatory Physiology, vol. 301, no. 4, pp. H1513-H1518, 2011.

[46] O. Yermolaieva, R. Xu, C. Schinstock et al., "Methionine sulfoxide reductase A protects neuronal cells against brief hypoxia/reoxygenation," Proceedings of the National Academy of Sciences of the United States of America, vol. 101, no. 5, pp. 11591164, 2004.

[47] J. I. Kim, S. H. Choi, K. J. Jung, E. Lee, H. Y. Kim, and K. M. Park, "Protective role of methionine sulfoxide reductase A against ischemia/reperfusion injury in mouse kidney and its involvement in the regulation of trans-sulfuration pathway," Antioxidants \& Redox Signaling, vol. 18, pp. 2241-2250, 2013.

[48] L. I. Leichert, F. Gehrke, H. V. Gudiseva et al., "Quantifying changes in the thiol redox proteome upon oxidative stress in vivo," Proceedings of the National Academy of Sciences of the United States of America, vol. 105, no. 24, pp. 8197-8202, 2008.

[49] B. Chull An, S. Sik Lee, E. Mi Lee, S. Gon Wi, W. Park, and B. Yeoup Chung, "Global analysis of disulfide bond proteins 
in Pseudomonas aeruginosa exposed to hydrogen peroxide and gamma rays," International Journal of Radiation Biology, vol. 86, no. 5, pp. 400-408, 2010.

[50] T. E. Danciu and M. Whitman, "Oxidative stress drives disulfide bond formation between basic helix-loop-helix transcription factors," Journal of Cellular Biochemistry, vol. 109, no. 2, pp. 417424, 2010.

[51] R. C. Cumming, N. L. Andon, P. A. Haynes, M. Park, W. H. Fischer, and D. Schubert, "Protein disulfide bond formation in the cytoplasm during oxidative stress," The Journal of Biological Chemistry, vol. 279, no. 21, pp. 21749-21758, 2004.

[52] A. Sommer and R. R. Traut, "Diagonal polyacrylamide dodecyl sulfate gel electrophoresis for the identification of ribosomal proteins crosslinked with methyl 4 mercaptobutyrimidate," Proceedings of the National Academy of Sciences of the United States of America, vol. 71, no. 10, pp. 3946-3950, 1974.

[53] C. M. Cremers and U. Jakob, "Oxidant sensing by reversible disulfide bond formation," The Journal of Biological Chemistry, vol. 288, pp. 26489-26496, 2013.

[54] A. Pastore and F. Piemonte, "S-glutathionylation signaling in cell biology: progress and prospects," European Journal of Pharmaceutical Sciences, vol. 46, pp. 279-292, 2012.

[55] A. Muller, J. H. Hoffmann, H. E. Meyer, F. Narberhaus, U. Jakob, and L. I. Leichert, "Nonnative disulfide bond formation activates the sigma32-dependent heat shock response in Escherichia coli," Journal of Bacteriology, vol. 195, pp. 2807-2816, 2013.

[56] P. Venditti, L. di Stefano, and S. di Meo, "Mitochondrial metabolism of reactive oxygen species," Mitochondrion, vol. 13, pp. 71-82, 2013.

[57] J. St-Pierre, J. A. Buckingham, S. J. Roebuck, and M. D. Brand, "Topology of superoxide production from different sites in the mitochondrial electron transport chain," The Journal of Biological Chemistry, vol. 277, no. 47, pp. 44784-44790, 2002.

[58] S. Miwa, J. St-Pierre, L. Partridge, and M. D. Brand, "Superoxide and hydrogen peroxide production by Drosophila mitochondria," Free Radical Biology and Medicine, vol. 35, no. 8, pp. 938948, 2003.

[59] S. Drose and U. Brandt, "Molecular mechanisms of superoxide production by the mitochondrial respiratory chain," Advances in Experimental Medicine and Biology, vol. 748, pp. 145-169, 2012.

[60] I. Siebels and S. Drose, "Q-site inhibitor induced ROS production of mitochondrial complex II is attenuated by TCA cycle dicarboxylates," Biochimica et Biophysica Acta, vol. 1827, pp. 1156-1164, 2013.

[61] L. J. Yan, N. Thangthaeng, N. Sumien, and M. J. Forster, "Serum Dihydrolipoamide Dehydrogenase is a Labile enzyme," Journal of Biochemical and Pharmacological Research, vol. 1, pp. 30-42, 2013.

[62] A. A. Starkov, G. Fiskum, C. Chinopoulos et al., "Mitochondrial $\alpha$-ketoglutarate dehydrogenase complex generates reactive oxygen species," The Journal of Neuroscience, vol. 24, no. 36, pp. 7779-7788, 2004.

[63] A. Ambrus, L. Tretter, and V. Adam-Vizi, "Inhibition of the alpha-ketoglutarate dehydrogenase-mediated reactive oxygen species generation by lipoic acid," Journal of Neurochemistry, vol. 109, supplement 1, pp. 222-229, 2009.

[64] A. Ambrus, B. Torocsik, L. Tretter, O. Ozohanics, and V. Adam-Vizi, "Stimulation of reactive oxygen species generation by disease-causing mutations of lipoamide dehydrogenase," Human Molecular Genetics, vol. 20, no. 15, pp. 2984-2995, 2011.
[65] A. Ambrus and V. Adam-Vizi, "Molecular dynamics study of the structural basis of dysfunction and the modulation of reactive oxygen species generation by pathogenic mutants of human dihydrolipoamide dehydrogenase," Archives of Biochemistry and Biophysics, vol. 538, pp. 145-155, 2013.

[66] A. Manea, "NADPH oxidase-derived reactive oxygen species: involvement in vascular physiology and pathology," Cell and Tissue Research, vol. 342, no. 3, pp. 325-339, 2010.

[67] J. Bylund, K. L. Brown, C. Movitz, C. Dahlgren, and A. Karlsson, "Intracellular generation of superoxide by the phagocyte NADPH oxidase: how, where, and what for?" Free Radical Biology and Medicine, vol. 49, no. 12, pp. 1834-1845, 2010.

[68] R. Harrison, "Physiological roles of xanthine oxidoreductase," Drug Metabolism Reviews, vol. 36, no. 2, pp. 363-375, 2004.

[69] A. Agarwal, A. Banerjee, and U. C. Banerjee, "Xanthine oxidoreductase: a journey from purine metabolism to cardiovascular excitation-contraction coupling," Critical Reviews in Biotechnology, vol. 31, no. 3, pp. 264-280, 2011.

[70] L. Mandelker, "Introduction to oxidative stress and mitochondrial dysfunction," Veterinary Clinics of North America-Small Animal Practice, vol. 38, no. 1, pp. 1-30, 2008.

[71] C. L. Quinlan, R. L. Goncalves, M. Hey-Mogensen, N. Yadava, V. I. Bunik, and M. D. Brand, "The 2-oxoacid dehydrogenase complexes in mitochondria can produce superoxide/hydrogen peroxide at much higher rates than complex I," The Journal of Biological Chemistry, 2014.

[72] P. J. Kiley and G. Storz, "Exploiting thiol modifications," PLoS Biology, vol. 2, no. 11, article e400, 2004.

[73] J. F. Turrens, "Superoxide production by the mitochondrial respiratory chain," Bioscience Reports, vol. 17, no. 1, pp. 3-8, 1997.

[74] J. F. Turrens, A. Alexandre, and A. L. Lehninger, "Ubisemiquinone is the electron donor for superoxide formation by complex III of heart mitochondria," Archives of Biochemistry and Biophysics, vol. 237, no. 2, pp. 408-414, 1985.

[75] B. N. Ames and M. K. Shigenaga, "Oxidants are a major contributor to aging," Annals of the New York Academy of Sciences, vol. 663, pp. 85-96, 1992.

[76] C. Szabó, H. Ischiropoulos, and R. Radi, "Peroxynitrite: biochemistry, pathophysiology and development of therapeutics," Nature Reviews Drug Discovery, vol. 6, no. 8, pp. 662-680, 2007.

[77] J. J. Poderoso, "The formation of peroxynitrite in the applied physiology of mitochondrial nitric oxide," Archives of Biochemistry and Biophysics, vol. 484, no. 2, pp. 214-220, 2009.

[78] R. Radi, A. Cassina, R. Hodara, C. Quijano, and L. Castro, "Peroxynitrite reactions and formation in mitochondria," Free Radical Biology and Medicine, vol. 33, no. 11, pp. 1451-1464, 2002.

[79] B. Alvarez and R. Radi, "Peroxynitrite reactivity with amino acids and proteins," Amino Acids, vol. 25, no. 3-4, pp. 295-311, 2003.

[80] L. A. Sena and N. S. Chandel, "Physiological roles of mitochondrial reactive oxygen species," Molecular Cell, vol. 48, pp. 158167, 2012.

[81] R. J. Mailloux, X. Jin, and W. G. Willmore, "Redox regulation of mitochondrial function with emphasis on cysteine oxidation reactions," Redox Biology, vol. 2, pp. 123-139, 2013.

[82] N. Kondo, H. Nakamura, H. Masutani, and J. Yodoi, "Redox regulation of human thioredoxin network," Antioxidants and Redox Signaling, vol. 8, no. 9-10, pp. 1881-1890, 2006.

[83] N. L. Malinin, X. Z. West, and T. V. Byzova, "Oxidation as 'the stress of life”, Aging, vol. 3, no. 9, pp. 906-910, 2011. 
[84] C. Gorrini, I. S. Harris, and T. W. Mak, "Modulation of oxidative stress as an anticancer strategy," Nature Reviews Drug Discovery, vol. 12, pp. 931-947, 2013.

[85] A. M. Pickering, L. Vojtovich, J. Tower, and K. J. A Davies, "Oxidative stress adaptation with acute, chronic, and repeated stress," Free Radical Biology and Medicine, vol. 55, pp. 109-118, 2013.

[86] K. J. A. Davies, "Oxidative stress, antioxidant defenses, and damage removal, repair, and replacement systems," IUBMB Life, vol. 50, no. 4-5, pp. 279-289, 2000.

[87] I. Milisav, B. Poljsak, and D. Suput, "Adaptive response, evidence of cross-resistance and its potential clinical use," International Journal of Molecular Sciences, vol. 13, pp. 10771-10806, 2012.

[88] V. Calabrese, C. Cornelius, S. Cuzzocrea, I. Iavicoli, E. Rizzarelli, and E. J. Calabrese, "Hormesis, cellular stress response and vitagenes as critical determinants in aging and longevity," Molecular Aspects of Medicine, vol. 32, no. 4-6, pp. 279-304, 2011.

[89] A. Luna-Lopez, V. Y. Gonzalez-Puertos, J. Romero-Ontiveros et al., "A noncanonical NF-kappaB pathway through the p50 subunit regulates $\mathrm{Bcl}-2$ overexpression during an oxidativeconditioning hormesis response," Free Radical Biology and Medicine, vol. 63, pp. 41-50, 2013.

[90] G. Lopez-Martinez and D. A. Hahn, "Early life hormetic treatments decrease irradiation-induced oxidative damage, increase longevity, and enhance sexual performance during old age in the Caribbean fruit fly," PLoS ONE, vol. 9, Article ID e88128, 2014.

[91] M. Ristow and S. Schmeisser, "Extending life span by increasing oxidative stress," Free Radical Biology and Medicine, vol. 51, supplement 2, pp. 327-336, 2011.

[92] M. Blanco, I. Lizasoain, T. Sobrino, J. Vivancos, and J. Castillo, "Ischemic preconditioning: a novel target for neuroprotective therapy," Cerebrovascular Diseases, vol. 21, no. 2, pp. 38-47, 2006.

[93] S. Shiva, M. N. Sack, J. J. Greer et al., "Nitrite augments tolerance to ischemia/reperfusion injury via the modulation of mitochondrial electron transfer," Journal of Experimental Medicine, vol. 204, no. 9, pp. 2089-2102, 2007.

[94] M. R. Bigdeli, "Neuroprotection caused by hyperoxia preconditioning in animal stroke models," TheScientificWorldJournal, vol. 11, pp. 403-421, 2011.

[95] Y. Soejima, Q. Hu, P. R. Krafft, M. Fujii, J. Tang, and J. H. Zhang, "Hyperbaric oxygen preconditioning attenuates hyperglycemia-enhanced hemorrhagic transformation by inhibiting matrix metalloproteinases in focal cerebral ischemia in rats," Experimental Neurology, vol. 247, pp. 737-743, 2013.

[96] A. M. Stowe, T. Altay, A. B. Freie, and J. M. Gidday, "Repetitive hypoxia extends endogenous neurovascular protection for stroke," Annals of Neurology, vol. 69, no. 6, pp. 975-985, 2011.

[97] Z. Sedaghat, M. Kadkhodaee, B. Seifi, E. Salehi, A. Najafi, and L. Dargahi, "Remote preconditioning reduces oxidative stress, downregulates cyclo-oxygenase- 2 expression and attenuates ischaemia-reperfusion-induced acute kidney injury," Clinical and Experimental Pharmacology and Physiology, vol. 40, pp. 97103, 2013.

[98] J. Vinten-Johansen, Z. Zhao, A. J. Zatta, H. Kin, M. E. Halkos, and F. Kerendi, "Postconditioning: a new link in nature's armor against myocardial ischemia-reperfusion injury," Basic Research in Cardiology, vol. 100, no. 4, pp. 295-310, 2005.
[99] H. Zhao, "The protective effect of ischemic postconditioning against ischemic injury: from the heart to the brain," Journal of Neuroimmune Pharmacology, vol. 2, no. 4, pp. 313-318, 2007.

[100] H. Zhao, "Ischemic postconditioning as a novel avenue to protect against brain injury after stroke," Journal of Cerebral Blood Flow and Metabolism, vol. 29, no. 5, pp. 873-885, 2009.

[101] H. Zhao, C. Ren, X. Chen, and J. Shen, "From rapid to delayed and remote postconditioning: the evolving concept of ischemic postconditioning in brain ischemia," Current Drug Targets, vol. 13, no. 2, pp. 173-187, 2012.

[102] H. Zhao, R. M. Sapolsky, and G. K. Steinberg, "Interrupting reperfusion as a stroke therapy: ischemic postconditioning reduces infarct size after focal ischemia in rats," Journal of Cerebral Blood Flow and Metabolism, vol. 26, no. 9, pp. 1114-1121, 2006.

[103] D. P. Davis and P. M. Patel, "Ischemic preconditioning in the brain," Current Opinion in Anaesthesiology, vol. 16, no. 5, pp. 447-452, 2003.

[104] W. Kwok and K. Aizawa, "Preconditioning of the myocardium by volatile anesthetics," Current Medicinal Chemistry: Cardiovascular and Hematological Agents, vol. 2, no. 3, pp. 249-255, 2004.

[105] C. Penna, D. Mancardi, R. Rastaldo, and P. Pagliaro, "Cardioprotection: a radical view. Free radicals in pre and postconditioning," Biochimica et Biophysica Acta-Bioenergetics, vol. 1787, no. 7, pp. 781-793, 2009.

[106] F. Tullio, C. Angotti, M. G. Perrelli, C. Penna, and P. Pagliaro, "Redox balance and cardioprotection," Basic Research in Cardiology, vol. 108, article 392, 2013.

[107] E. Murphy and C. Steenbergen, "Mechanisms underlying acute protection from cardiac ischemia-reperfusion injury," Physiological Reviews, vol. 88, no. 2, pp. 581-609, 2008.

[108] Y. Go and D. P. Jones, "Redox compartmentalization in eukaryotic cells," Biochimica et Biophysica Acta-General Subjects, vol. 1780, no. 11, pp. 1273-1290, 2008.

[109] Y. M. Go and D. P. Jones, "Thiol/disulfide redox states in signaling and sensing," Critical Reviews in Biochemistry and Molecular Biology, vol. 48, pp. 173-181, 2013.

[110] S. A. Lipton, Y. Choi, H. Takahashi et al., "Cysteine regulation of protein function-as exemplified by NMDA-receptor modulation," Trends in Neurosciences, vol. 25, no. 9, pp. 474-480, 2002.

[111] N. Brandes, S. Schmitt, and U. Jakob, "Thiol-based redox switches in eukaryotic proteins," Antioxidants and Redox Signaling, vol. 11, no. 5, pp. 997-1014, 2009.

[112] F. Li, P. Sonveaux, Z. N. Rabbani et al., "Regulation of HIF-1 $\alpha$ stability through S-nitrosylation," Molecular Cell, vol. 26, no. 1, pp. 63-74, 2007.

[113] D. E. Fomenko, S. M. Marino, and V. N. Gladyshev, "Functional diversity of cysteine residues in proteins and unique features of catalytic redox-active cysteines in thiol oxidoreductases," Molecules and Cells, vol. 26, no. 3, pp. 228-235, 2008.

[114] H. J. Forman, J. M. Fukuto, T. Miller, H. Zhang, A. Rinna, and S. Levy, "The chemistry of cell signaling by reactive oxygen and nitrogen species and 4-hydroxynonenal," Archives of Biochemistry and Biophysics, vol. 477, no. 2, pp. 183-195, 2008.

[115] L. B. Poole, C. Klomsiri, S. A. Knaggs et al., "Fluorescent and affinity-based tools to detect cysteine sulfenic acid formation in proteins," Bioconjugate Chemistry, vol. 18, no. 6, pp. 2004-2017, 2007.

[116] S. R. Jaffrey and S. H. Snyder, "The biotin switch method for the detection of S-nitrosylated proteins," Science's STKE: Signal 
Transduction Knowledge Environment, vol. 2001, no. 86, article pl1, 2001.

[117] L. J. Yan, L. Liu, and M. J. Forster, "Reversible inactivation of dihydrolipoamide dehydrogenase by Angeli's salt," Acta Biophysica Sinica, vol. 28, pp. 341-350, 2012.

[118] B. Huang and C. Chen, "An ascorbate-dependent artifact that interferes with the interpretation of the biotin switch assay," Free Radical Biology and Medicine, vol. 41, no. 4, pp. 562-567, 2006.

[119] A. T. Saurin, H. Neubert, J. P. Brennan, and P. Eaton, "Widespread sulfenic acid formation in tissues in response to hydrogen peroxide," Proceedings of the National Academy of Sciences of the United States of America, vol. 101, no. 52, pp. 17982-17987, 2004.

[120] S. W. Aesif, Y. M. W. Janssen-Heininger, and N. L. Reynaert, "Protocols for the detection of s-glutathionylated and snitrosylated proteins in situ," Methods in Enzymology, vol. 474, pp. 289-296, 2010.

[121] J. Guo, M. J. Gaffrey, D. Su et al., "Resin-assisted enrichment of thiols as a general strategy for proteomic profiling of cysteinebased reversible modifications," Nature Protocols, vol. 9, pp. 6475, 2014.

[122] R. L. Charles, E. Schröder, G. May et al., "Protein sulfenation as a redox sensor: proteomics studies using a novel biotinylated dimedone analogue," Molecular and Cellular Proteomics, vol. 6, no. 9, pp. 1473-1484, 2007.

[123] C. Klomsiri, K. J. Nelson, E. Bechtold et al., "Use of dimedonebased chemical probes for sulfenic acid detection evaluation of conditions affecting probe incorporation into redox-sensitive proteins," Methods in Enzymology, vol. 473, pp. 77-94, 2010.

[124] K. Kaiserova, S. Srivastava, J. D. Hoetker et al., "Redox activation of aldose reductase in the ischemic heart," The Journal of Biological Chemistry, vol. 281, no. 22, pp. 15110-15120, 2006.

[125] K. Kaiserova, X. Tang, S. Srivastava, and A. Bhatnagar, "Role of nitric oxide in regulating aldose reductase activation in the ischemic heart," The Journal of Biological Chemistry, vol. 283, no. 14, pp. 9101-9112, 2008.

[126] I. N. Singh, P. G. Sullivan, and E. D. Hall, "Peroxynitritemediated oxidative damage to brain mitochondria: protective effects of peroxynitrite scavengers," Journal of Neuroscience Research, vol. 85, no. 10, pp. 2216-2223, 2007.

[127] E. Kilic, Ü. Kilic, Y. Wang, C. L. Bassetti, H. H. Marti, and D. M. Hermann, "The phosphatidylinositol-3 kinase/Akt pathway mediates VEGF's neuroprotective activity and induces blood brain barrier permeability after focal cerebral ischemia," The FASEB Journal, vol. 20, no. 8, pp. E307-E314, 2006.

[128] X. Yu, G. Jia, G. Gao, S. Wang, Y. Han, and W. Cao, "Neuroprotection of insulin against oxidative stress-induced apoptosis in cultured retinal neurons: involvement of phosphoinositide 3-kinase/Akt signal pathway," Acta Biochimica et Biophysica Sinica, vol. 38, no. 4, pp. 241-248, 2006.

[129] K. Wetzelberger, S. P. Baba, M. Thirunavukkarasu et al., "Postischemic deactivation of cardiac aldose reductase: role of glutathione S-transferase P and glutaredoxin in regeneration of reduced thiols from sulfenic acids," The Journal of Biological Chemistry, vol. 285, no. 34, pp. 26135-26148, 2010.

[130] M. W. Foster, D. T. Hess, and J. S. Stamler, "Protein Snitrosylation in health and disease: a current perspective," Trends in Molecular Medicine, vol. 15, no. 9, pp. 391-404, 2009.

[131] M. W. Foster, T. J. McMahon, and J. S. Stamler, "S-nitrosylation in health and disease," Trends in Molecular Medicine, vol. 9, no. 4, pp. 160-168, 2003.
[132] S. J. Chinta and J. K. Andersen, "Nitrosylation and nitration of mitochondrial complex i in Parkinson's disease," Free Radical Research, vol. 45, no. 1, pp. 53-58, 2011.

[133] D. M. Barrett, S. M. Black, H. Todor, R. K. Schmidt-Ullrich, K. S. Dawson, and R. B. Mikkelsen, "Inhibition of proteintyrosine phosphatases by mild oxidative stresses is dependent on S-nitrosylation," The Journal of Biological Chemistry, vol. 280, no. 15, pp. 14453-14461, 2005.

[134] E. Murphy, M. Kohr, J. Sun, T. Nguyen, and C. Steenbergen, "S-nitrosylation: a radical way to protect the heart," Journal of Molecular and Cellular Cardiology, vol. 52, no. 3, pp. 568-577, 2012.

[135] A. M. Evangelista, M. J. Kohr, and E. Murphy, "S-nitrosylation: specificity, occupancy, and interaction with other posttranslational modifications," Antioxidants \& Redox Signaling, vol. 19, pp. 1209-1219, 2013.

[136] G. Tong, A. M. Aponte, M. J. Kohr, C. Steenbergen, E. Murphy, and J. Sun, "Postconditioning leads to an increase in protein Snitrosylation," The American Journal of Physiology-Heart and Circulatory Physiology, vol. 306, no. 6, pp. H825-H832, 2014.

[137] M. J. Kohr, A. M. Evangelista, M. Ferlito, C. Steenbergen, and E. Murphy, "S-nitrosylation of TRIM72 at cysteine 144 is critical for protection against oxidation-induced protein degradation and cell death," Journal of Molecular and Cellular Cardiology, vol. 69, pp. 67-74, 2014.

[138] X. Yang, M. V. Cohen, and J. M. Downey, "Mechanism of cardioprotection by early ischemic preconditioning," Cardiovascular Drugs and Therapy, vol. 24, no. 3, pp. 225-234, 2010.

[139] L. Yan, S. Yang, H. Shu, L. Prokai, and M. J. Forster, "Histochemial staining and qualification of dihydrolipoamide dehydrogenase diaphorase activity using blue native PAGE," Electrophoresis, vol. 28, no. 7, pp. 1036-1045, 2007.

[140] E. R. Taylor, F. Hurrell, R. J. Shannon, T. Lin, J. Hirst, and M. P. Murphy, "Reversible glutathionylation of complex I increases mitochondrial superoxide formation," The Journal of Biological Chemistry, vol. 278, no. 22, pp. 19603-19610, 2003.

[141] B. Andrews, J. Carroll, S. Ding, I. M. Fearnley, and J. E. Walker, "Assembly factors for the membrane arm of human complex I," Proceedings of the National Academy of Sciences of the United States of America, vol. 110, pp. 18934-18939, 2013.

[142] J. Hirst, "Mitochondrial complex I," Annual Review of Biochemistry, vol. 82, pp. 551-575, 2013.

[143] M. A. Moro, A. Almeida, J. P. Bolaños, and I. Lizasoain, "Mitochondrial respiratory chain and free radical generation in stroke," Free Radical Biology and Medicine, vol. 39, no. 10, pp. 1291-1304, 2005.

[144] E. Fassone and S. Rahman, "Complex I deficiency: clinical features, biochemistry and molecular genetics," Journal of Medical Genetics, vol. 49, pp. 578-590, 2012.

[145] A. H. V. Schapira, J. M. Cooper, D. Dexter, J. B. Clark, P. Jenner, and C. D. Marsden, "Mitochondrial Complex I deficiency in Parkinson's disease," Journal of Neurochemistry, vol. 54, no. 3, pp. 823-827, 1990.

[146] E. T. Chouchani, C. Methner, S. M. Nadtochiy et al., "Cardioprotection by S-nitrosation of a cysteine switch on mitochondrial complex I," Nature Medicine, vol. 19, pp. 753-759, 2013.

[147] C. S. F. Queiroga, A. S. Almeida, C. Martel, C. Brenner, P. M. Alves, and H. L. A. Vieira, "Glutathionylation of adenine nucleotide translocase induced by carbon monoxide prevents mitochondrial membrane permeabilization and apoptosis," The Journal of Biological Chemistry, vol. 285, no. 22, pp. 17077-17088, 2010. 
[148] L. Yan, E. S. Christians, L. Liu, X. Xiao, R. S. Sohal, and I. J. Benjamin, "Mouse heat shock transcription factor 1 deficiency alters cardiac redox homeostasis and increases mitochondrial oxidative damage," The EMBO Journal, vol. 21, no. 19, pp. 5164$5172,2002$.

[149] G. Sánchez, Z. Pedrozo, R. J. Domenech, C. Hidalgo, and P. Donoso, "Tachycardia increases NADPH oxidase activity and RyR2 S-glutathionylation in ventricular muscle," Journal of Molecular and Cellular Cardiology, vol. 39, no. 6, pp. 982-991, 2005.

[150] G. Sánchez, M. Escobar, Z. Pedrozo et al., "Exercise and tachycardia increase NADPH oxidase and ryanodine receptor2 activity: possible role in cardioprotection," Cardiovascular Research, vol. 77, no. 2, pp. 380-386, 2008.

[151] W. Li, J. Zhang, and W. An, "The conserved CXXC motif of hepatic stimulator substance is essential for its role in mitochondrial protection in $\mathrm{H}_{2} \mathrm{O}_{2}$-induced cell apoptosis," FEBS Letters, vol. 584, no. 18, pp. 3929-3935, 2010.

[152] Z. Guo, S. Kozlov, M. F. Lavin, M. D. Person, and T. T. Paull, "ATM activation by oxidative stress," Science, vol. 330, no. 6003, pp. 517-521, 2010.

[153] Y. Shimizu and L. M. Hendershot, "Oxidative folding: cellular strategies for dealing with the resultant equimolar production of reactive oxygen species," Antioxidants and Redox Signaling, vol. 11, no. 9, pp. 2317-2331, 2009.

[154] P. Ghezzi, "Oxidoreduction of protein thiols in redox regulation," Biochemical Society Transactions, vol. 33, no. 6, pp. 13781381, 2005.

[155] C. A. O'Brian and F. Chu, "Post-translational disulfide modifications in cell signaling-role of inter-protein, intra-protein, S-glutathionyl, and S-cysteaminyl disulfide modifications in signal transmission," Free Radical Research, vol. 39, no. 5, pp. 471-480, 2005.

[156] S. Fourquet, R. Guerois, D. Biard, and M. B. Toledano, "Activation of NRF2 by nitrosative agents and $\mathrm{H}_{2} \mathrm{O}_{2}$ involves KEAP1 disulfide formation," The Journal of Biological Chemistry, vol. 285, no. 11, pp. 8463-8471, 2010.

[157] A. Alfieri, S. Srivastava, R. C. M. Siow, M. Modo, P. A. Fraser, and G. E. Mann, "Targeting the Nrf2-Keap1 antioxidant defence pathway for neurovascular protection in stroke," The Journal of Physiology, vol. 589, no. 17, pp. 4125-4136, 2011.

[158] M. O. Leonard, N. E. Kieran, K. Howell et al., "Reoxygenationspecific activation of the antioxidant transcription factor $\mathrm{Nrf} 2$ mediates cytoprotective gene expression in ischemiareperfusion injury," The FASEB Journal, vol. 20, no. 14, pp. 26242626,2006

[159] K. Umemura, T. Itoh, N. Hamada et al., "Preconditioning by sesquiterpene lactone enhances $\mathrm{H}_{2} \mathrm{O}_{2}$-induced Nrf2/ARE activation," Biochemical and Biophysical Research Communications, vol. 368, no. 4, pp. 948-954, 2008.

[160] K. F. Bell, B. Al-Mubarak, J. H. Fowler et al., "Mild oxidative stress activates Nrf2 in astrocytes, which contributes to neuroprotective ischemic preconditioning," Proceedings of the National Academy of Sciences of the United States of America, vol. 108, no. 1, pp. E1-E4, 2011.

[161] K. F. S. Bell, J. H. Fowler, B. Al-Mubarak, K. Horsburgh, and G. E. Hardingham, "Activation of Nrf2-regulated glutathione pathway genes by ischemic preconditioning," Oxidative Medicine and Cellular Longevity, vol. 2011, Article ID 689524, 7 pages, 2011.

[162] W. C. Li, R. Jiang, D. M. Jiang et al., "Lipopolysaccharide preconditioning attenuates apoptotic processesand improves neuropathologic changes after spinal cord injury in rats," International Journal of Neuroscience. In press.

[163] J. W. Thompson, S. V. Narayanan, and M. A. Perez-Pinzon, "Redox signaling pathways involved in neuronal ischemic preconditioning," Current Neuropharmacology, vol. 10, pp. 354369, 2012.

[164] X. S. Huang, H. P. Chen, H. H. Yu, Y. F. Yan, Z. P. Liao, and Q. R. Huang, "Nrf2-dependent upregulation of antioxidative enzymes: a novel pathway for hypoxic preconditioningmediated delayed cardioprotection," Molecular and Cellular Biochemistry, vol. 385, pp. 33-41, 2014.

[165] A. Alfieri, S. Srivastava, R. C. Siow et al., "Sulforaphane preconditioning of the $\mathrm{Nrf} 2 / \mathrm{HO}-1$ defense pathway protects the cerebral vasculature against blood-brain barrier disruption and neurological deficits in stroke," Free Radical Biology and Medicine, vol. 65, pp. 1012-1022, 2013.

[166] C. Guo, F. Liang, W. Shah Masood, and X. Yan, "Hydrogen sulfide protected gastric epithelial cell from ischemia/reperfusion injury by Keapl s-sulfhydration, MAPK dependent antiapoptosis and NF-kappaB dependent anti-inflammation pathway," European Journal of Pharmacology, vol. 725, pp. 70-78, 2014.

[167] A. K. Jaiswal, "Nrf2 signaling in coordinated activation of antioxidant gene expression," Free Radical Biology and Medicine, vol. 36, no. 10, pp. 1199-1207, 2004.

[168] L. Baird and A. T. Dinkova-Kostova, "The cytoprotective role of the Keap1-Nrf2 pathway," Archives of Toxicology, vol. 85, no. 4, pp. 241-272, 2011.

[169] E. Kansanen, S. M. Kuosmanen, H. Leinonen, and A. L. Levonen, "The Keap1-Nrf2 pathway: mechanisms of activation and dysregulation in cancer," Redox Biology, vol. 1, pp. 45-49, 2013.

[170] L. M. Shelton, B. K. Park, and I. M. Copple, "Role of Nrf2 in protection against acute kidney injury," Kidney International, vol. 84, pp. 1090-1095, 2013.

[171] T. Suzuki, H. Motohashi, and M. Yamamoto, "Toward clinical application of the Keap1-Nrf2 pathway," Trends in Pharmacological Sciences, vol. 34, pp. 340-346, 2013.

[172] T. Ishii, O. Sunami, H. Nakajima, H. Nishio, T. Takeuchi, and F. Hata, "Critical role of sulfenic acid formation of thiols in the inactivation of glyceraldehyde-3-phosphate dehydrogenase by nitric oxide," Biochemical Pharmacology, vol. 58, no. 1, pp. 133143, 1999.

[173] M. D. Percival, M. Ouellet, C. Campagnolo, D. Claveau, and C. $\mathrm{Li}$, "Inhibition of cathepsin $\mathrm{K}$ by nitric oxide donors: evidence for the formation of mixed disulfides and a sulfenic acid," Biochemistry, vol. 38, no. 41, pp. 13574-13583, 1999.

[174] K. K. Chung, "Say NO to neurodegeneration: role of Snitrosylation in neurodegenerative disorders," NeuroSignals, vol. 15, no. 6, pp. 307-313, 2006.

[175] J. Tian, S. F. Kim, L. Hester, and S. H. Snyder, "Snitrosylation/activation of COX-2 mediates NMDA neurotoxicity," Proceedings of the National Academy of Sciences of the United States of America, vol. 105, no. 30, pp. 10537-10540, 2008.

[176] E. R. Stadtman, "Protein oxidation and aging," Science, vol. 257, no. 5074, pp. 1220-1224, 1992.

[177] E. R. Stadtman, "Protein oxidation in aging and age-related diseases," Annals of the New York Academy of Sciences, vol. 928, pp. 22-38, 2001.

[178] E. R. Stadtman, "Protein oxidation and aging," Free Radical Research, vol. 40, no. 12, pp. 1250-1258, 2006. 
[179] E. R. Stadtman and R. L. Levine, "Free radical-mediated oxidation of free amino acids and amino acid residues in proteins," Amino Acids, vol. 25, no. 3-4, pp. 207-218, 2003.

[180] T. J. Jönsson, M. S. Murray, L. C. Johnson, and W. T. Lowther, "Reduction of cysteine sulfinic acid in peroxiredoxin by sulfiredoxin proceeds directly through a sulfinic phosphoryl ester intermediate," The Journal of Biological Chemistry, vol. 283, no. 35, pp. 23846-23851, 2008.

[181] T. J. Jönsson, A. W. Tsang, W. T. Lowther, and C. M. Furdui, "Identification of intact protein thiosulfinate intermediate in the reduction of cysteine sulfinic acid in peroxiredoxin by human sulfiredoxin," The Journal of Biological Chemistry, vol. 283, no. 34, pp. 22890-22894, 2008. 


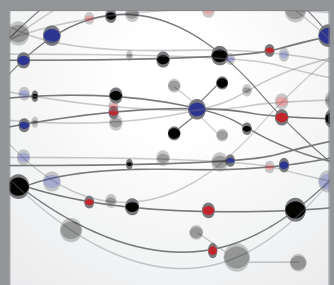

The Scientific World Journal
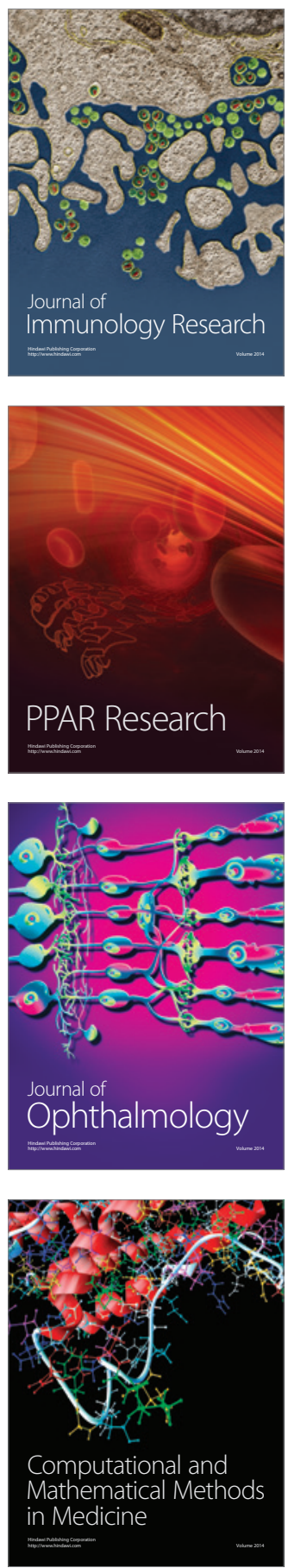

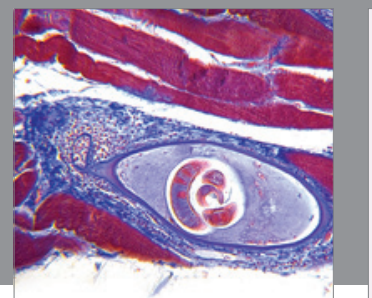

Gastroenterology

Research and Practice
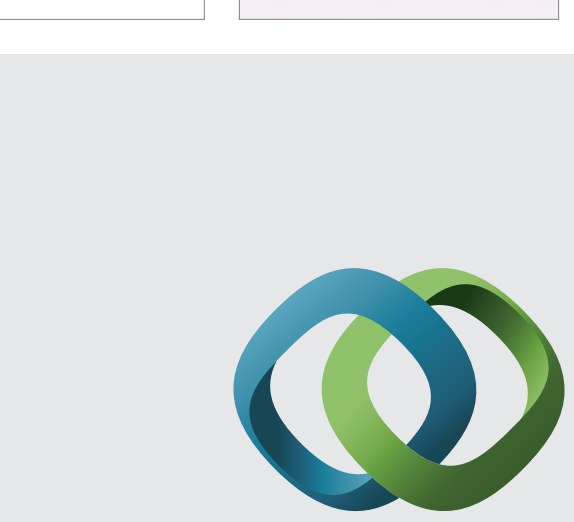

\section{Hindawi}

Submit your manuscripts at

http://www.hindawi.com
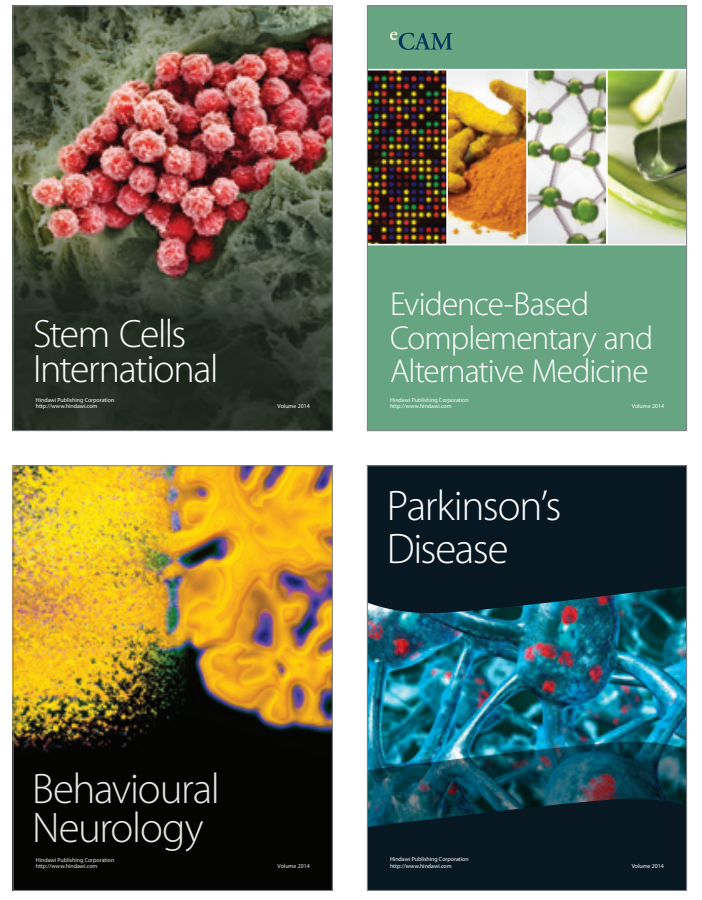
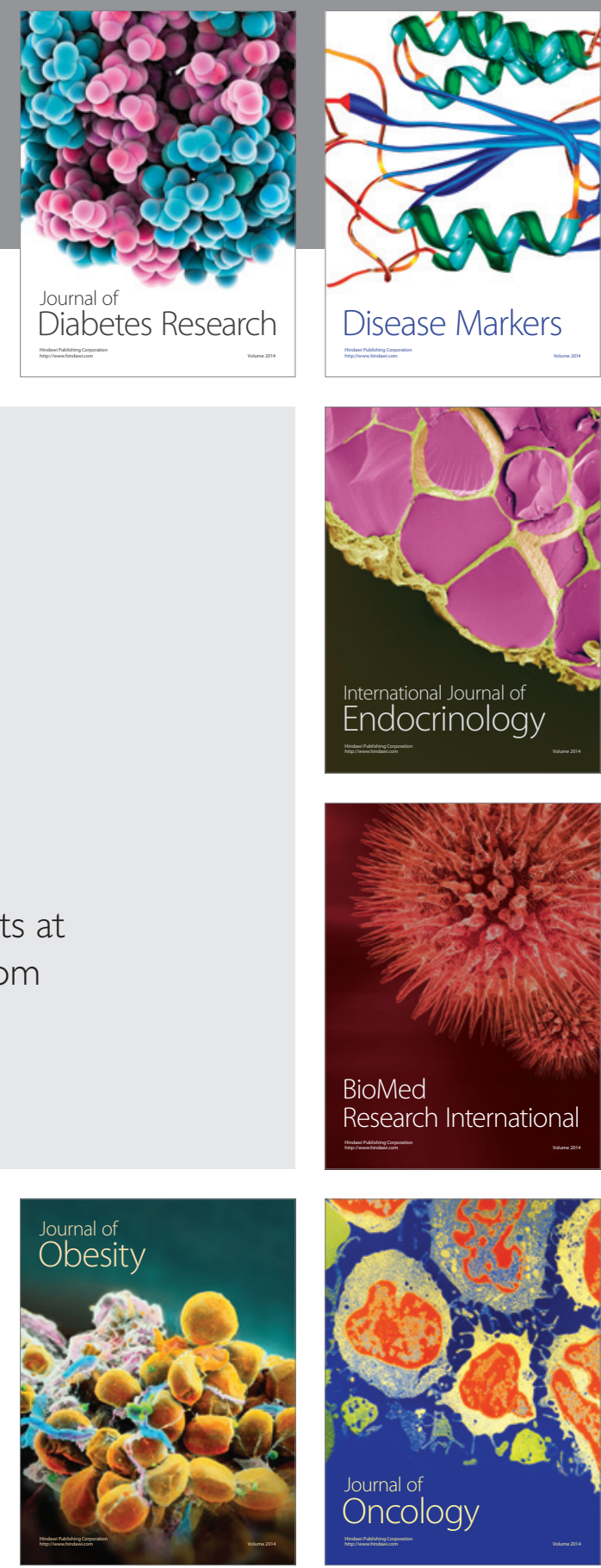

Disease Markers
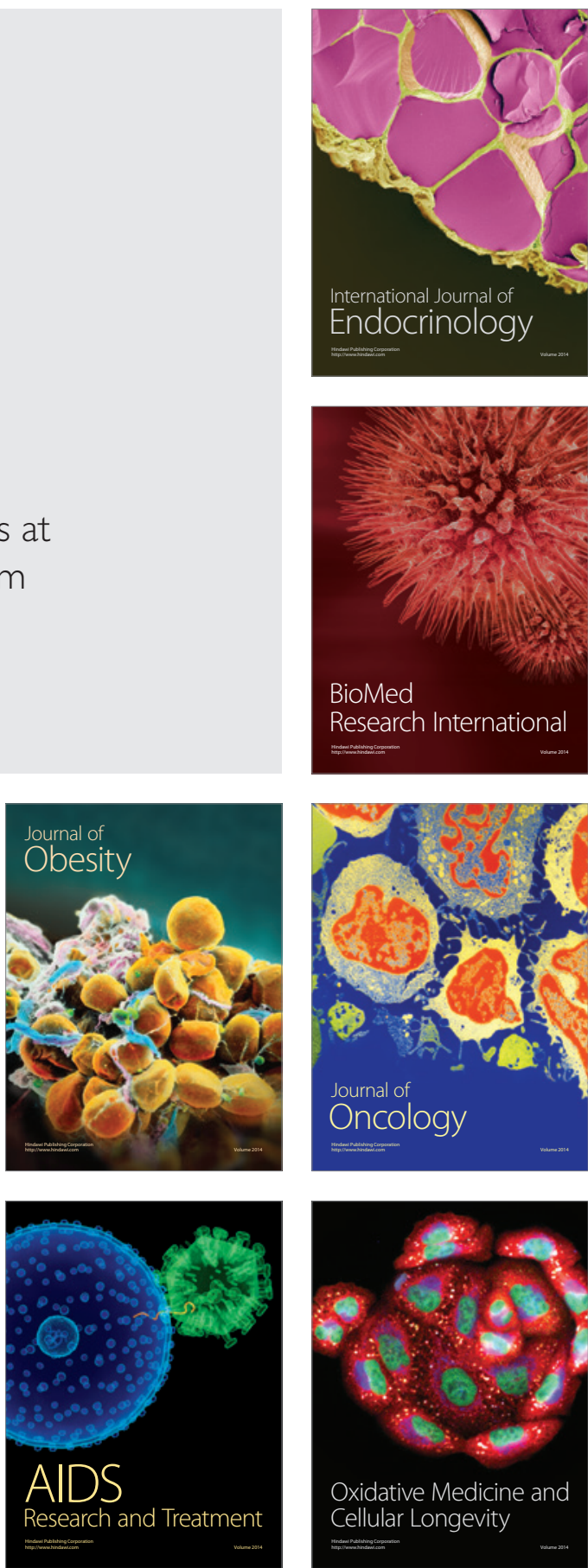